\title{
La comunicación afro y embera entre bosque, río y mar en el golfo de Tribugá, municipio de Nuquí, Chocó, Colombia
}

\section{Embera and Afro communication between forest, river and sea in the Gulf of Tribugá, municipality of Nuquí, Chocó, Colombia}

\author{
Jairo Miguel Guerra Gutiérrez¹, María Brenilde Uribe Lemus²
}

\section{Resumen}

El presente trabajo buscó identificar y caracterizar las diferentes estrategias de comunicación empleadas por las comunidades étnicas de Nuquí, Chocó, Colombia, quienes de acuerdo con sus condiciones de vida, las han desarrollado unas propias como mecanismo de interlocución y de conservación de su patrimonio cultural, pero que a la vez se han visto permeadas por nuevas tecnologías. La metodología utilizada para el levantamiento de la información fue la etnografía con observación participada, conversatorios, diálogos informales y sistematización confrontada con información secundaria. Los resultados obtenidos son una descripción y análisis del trance por el que atraviesa la comunicación embera y afro entre el celular, la televisión y la vivencia de unos medios tradicionales que subyacen en medio de las deficiencias de señales satelitales y apropiación de medios tecnológicos. Comunicar para los afros y los embera asentados en el área de Nuquí es un ejercicio que liga a la comunidad con el bosque, el río y el mar. Una bamba de carrá y un trozo de madera generó el número de golpes que comunicaba la necesidad de auxilio, ayuda o simplemente el hasta otro momento de la despedida de quien parte de la comunidad hacia otro lugar; la comunicación fluye por las orillas de la playa o del río, atravesando montes. En síntesis, objetos provenientes del mar o del bosque, aunados con la champa que se desliza por los cauces han sido tradicionalmente los canales por los que fluyen los mensajes que las personas o comunidades requieren comunicar.

Palabras clave: Comunicación afro, Comunicación embera, Comunicación tradicional, Comunidades étnicas, Nuquí.

\begin{abstract}
This study sought to identify and characterize the different communication strategies used by ethnic communities of Nuqui, Chocó, Colombia, who according to their conditions of life, have developed themselves as a mechanism for dialogue and conservation of their cultural heritage, but at the once they have been permeated by new technologies. The methodology used for gathering information was ethnography with investee observation, conversations, informal dialogues and systematization confronted with secondary information. The results are a description and analysis of the trance it goes across the Embera and Afro-cell communication, television and traditional media experience some underlying deficiencies through satellite signals and appropriation of technological means. Communicating for afros and Embera settled in the area of Nuqui is an exercise that links the community
\end{abstract}

1 Antropólogo. Asesor Instituto de Investigaciones Ambientales del Pacífico (IIAP), Quibdó, Colombia.

e-mail: jguerra@iiap.org.co

2 Comunicadora social y periodista. Coordinadora de Oficina de Comunicaciones del Instituto de Investigaciones Ambientales del Pacífico (IIAP), Chocó, Colombia. e-mail: muribe@iiap.org.co

Recibido: 13 de diciembre de 2013 Aprobado: 25 de marzo de 2014 


\section{Bioetnia Volumen 11, 2014}

with forest, river and sea. A bamba Carra and a piece of wood generated the number of strokes that communicated the need for help, help or simply to another moment of departure from whom the community to another place; communication flows along the banks of the beach or the river; through mountains. In short, objects from the sea or forest, coupled with the champagne that slides through the channels have traditionally been the channels through which messages flow that individuals or communities need to communicate.

Keywords: Afro communication, Communication Embera, Ethnic communities, Nuqui, Traditional communication.

\section{Introducción}

Bosque, mar y río han sido y son la fuente de comunicación de los individuos y las comunidades afros y embera asentadas en las orillas de la costa o los ríos que vierten sus aguas al océano. Sin embargo cuando se trata de indagar a las personas sobre comunicación, inmediatamente expresan la relación con el celular, el teléfono, la radio, la televisión y la prensa escrita a pesar de lo limitado que son estos medios.

Se requiere un mínimo de convivencia con las comunidades y más aún un proceso de investigación para lograr visibilizar la prevalencia de otras formas tradicionales de comunicación, como son los "chasques", utilizados para llevar mensajes en forma veloz sobre un accidente, una enfermedad o el fallecimiento de una persona; esta herramienta se mantiene, aún entre una población adulta que de una u otra forma a logrado legar a las nuevas generaciones en la medida que son los jóvenes diestros y rápidos, los encargados de llevar el mensaje. Subsiste el conocimiento de la función del churo o de la bamba para emitir mensajes cifrados tipo telégrafo en donde el mensaje está en relación con el número de impulsos; aún son vigentes en las comunidades la canoa mensajera, los caminos, las comisiones de razoneros, el envío de encomienda mano a mano con transeúnttes o viajeros. Este tipo de medio exige una alta fidelidad y respeto a la tradición, a la palabra, a los signos; cuando se hace un llamado debe ser preciso y con un motivo fundamentado; cuando se asume la responsabilidad de llevar o traer algo se debe cumplir, lo cual hace que las personas tengan credibilidad en los mismos. Por encima de la tradición, también vale la pena destacar el alto porcentaje en la entrega y decodificación del contenido; en la medida de que no existen interferencias técnicas que puedan distorsionar la originalidad del mensaje a transmitir o el riesgo de que éste nunca llegue.

La geografía estructurada por el bosque y la mar como área o escenario y los ríos y playas como conectores, resul- tan de suma importancia para entender el por qué medios ancestrales de comunicación mantienen vigencia ante una imponente eficacia del medio radial o celular. Respecto a los mensajes o productos de comunicación se centran en los acontecimientos de vida y muerte; lo más importante para comunicar son los motivos de fiestas, algunas permanentes año tras año, como las patronales y las navidades y otras ocasionales como los matrimonios, los cumpleaños, los gemené o fiestas de la muchacha, las visitas de personas o familias emigradas que retornan y las convocatorias a reuniones de diferente tipo. Por el lado de la muerte y el dolor siempre son ocasionales como una enfermedad, accidente o muerte y programadas como los cabo de mes y año de las muertes.

En el modus vivendi actual, donde los mayores permanecen en los conglomerados orilleros mientras los jóvenes salen a estudiar y aún los adultos salen en búsqueda de oportunidades de salud y trabajo a las cabeceras municipales y otros lugares más distantes, los medios tradicionales toman otras figuras como el "envío de la encomienda a mano"; el puerto o el aeropuerto son los puntos de contacto para encontrar a un emisario de buena voluntad que entendiendo la intención del otro con gusto y todo respeto hace el "favor" de llevar un paquete, una cantidad de dinero, un mensaje escrito o verbal, un repuesto o muestra del mismo o hasta una comida típica que será recibido por el destinatario en el punto de llegada.

Los acontecimientos que requieren de la comunicación entre vecinos, comunidades cercanas o aquellas en donde se encuentran familiares o amigos se convierten en necesidad y encuentran la manera de ser resuelta más allá de las tecnología modernas, aún siendo estas accesibles. Las vías de comunicación comunes son la canoa, el río y el mar pero en ocasiones se deben usar caminos o trochas monte traviesa que unen una cuenca con otra. Para el caso de las comunidades del golfo de Tribugá es común atravesar a la cuenca del Baudó o del Atrato en donde se encuentran parientes cercanos y con los que se mantienen relaciones cercanas de familiaridad.

\section{Contexto geográfico y metodológico}

La investigación se realizó en el área del golfo de Tribugá, municipio de Nuquí, Chocó, Colombia, con la participación de siete comunidades: tres afro, Apartadó, Termales y Joví y cuatro Embera, Yucal del río Panguí, Nuquí Arriba, Tandó del río Nuquí y puerto Jagua del río Chorí (Figura 1) (Mosquera 2012). Estas comunidades tienen una población aproximada de 1.900 habitantes; cada comunidad tiene alrededor de 300 habitantes los cuales mantienen como epicentro de servicios y mercadeo cercano en la cabecera municipal de Nuquí. En la parte remota para 


\section{Comunicación afro y embera. JM Guerra, MB Uribe}

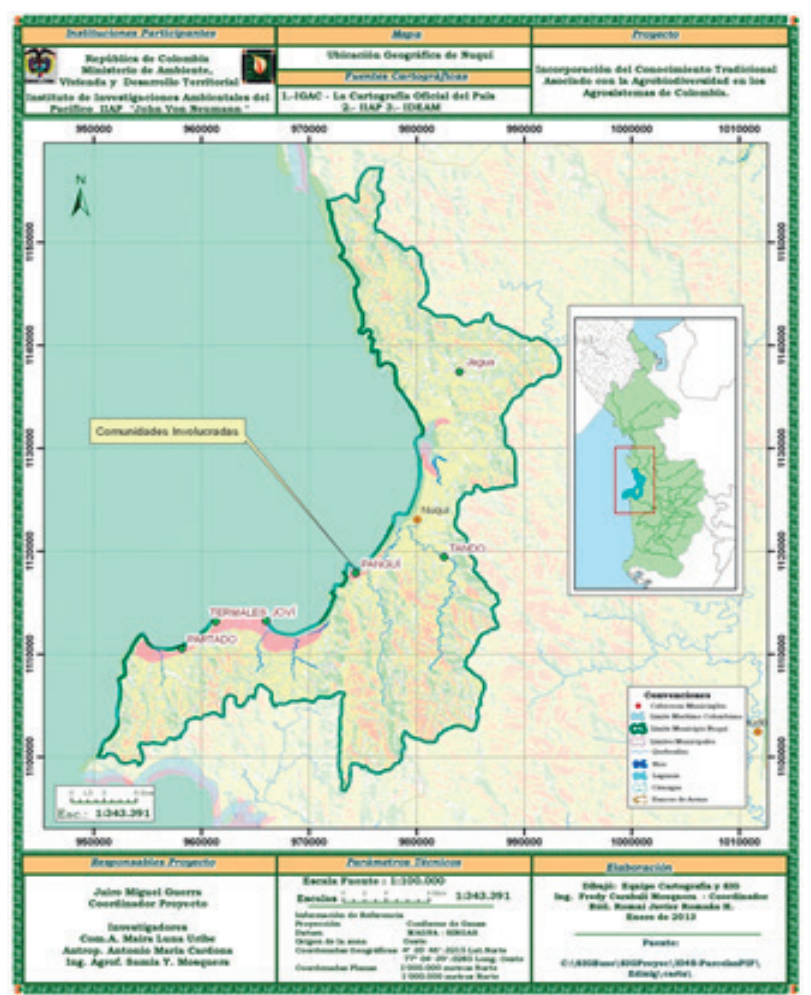

Figura 1. Ubicación de comunidades en el golfo de Tribugá.

aspectos administrativos, de educación, salud y mercados especializados se tiene a Quibdó, Bahía Solano y Buenaventura (Quintero 2012).

La ubicación de las comunidades afro es a la orilla de la playa en la desembocadura de ríos o quebradas que llevan el mismo nombre del pueblo; las familias tienen actividades productivas relacionadas con la pesca hacia el mar y agricultura hacia los ríos y quebradas. El transporte es en su mayoría personal en canoas y hay una ruta que transita entre Arusí al sur y Nuquí todos los días con dos embarcaciones que se alternan los días de la semana; en las primeras horas de la mañana sale de Arusí y pasan recogiendo pasajeros y encomiendas por los centros poblados de la playa y en las primeras horas de la tarde regresa. Algunos operadores turísticos tienen medio propio motorizado y prestan servicios ocasionales a los pobladores. También en las comunidades existe un promedio de 2 familias con embarcaciones motorizadas, empleadas principalmente para la pesca, pero en las cuales ocasionalmente prestan servicios de transporte.

Las comunidades indígenas se encuentran en la parte media de los ríos, a un promedio de 3 horas de desplazamiento en canoas impulsadas por palancas manuales desde la desembocadura del río hasta la comunidad y cuando los ríos tienen suficiente agua se hacen navegables y permiten transporte impulsado con motores, reduciendo el tiempo en una tercera parte. La única comunidad que tiene transporte motorizado casi permanente es puerto Jagua, para lo cual se debe contar con la marea alta con el fin de pasar la bocana del río Chorí.

Para el análisis de la información que se presenta se realizó un levantamiento de una línea base a partir de los datos contenidos en el Esquema de Ordenamiento Territorial del municipal de Nuquí, los censos de población de la escuela y la salud, las solicitudes de titulación territorial de resguardos indígenas o territorio colectivo y la resolución del título. Para el caso de las comunidades afro ubicadas en proximidades a Nuquí existen descripciones relacionadas con los estudios para la construcción de la vía al mar y el plan de etnodesarrollo formulado por los riscales; para las comunidades indígenas el estudio sociocultural y económico de las comunidades asentadas en el resguardo Jurubidá Chorí, Alto Baudó, realizado por el Consorcio Vía al Mar en asocio con la organización Acioquendo. La información primaria se levantó a través de aproximaciones etnográficas, utilizando instrumentos como la observación participada, guía de preguntas orientativas aplicadas en conversatorios comunitarios y diálogos interpersonales al azar, reforzado con entrevistas semiestructuradas con sabedores ancestrales.

\section{Características de la comunicación en comunidades étnicas}

Desde que el niño nace, para el caso Embera, es recibido en el agua e inicia a manejar las artes de dominio del agua, nadar, navegar y transportarse en chingos, champas y botes por el cauce del río o por el mar; reconocer los peces y pescar con diferentes artes; paralelamente entra al bosque, observa y aprende a cazar, sembrar y colectar diferentes productos naturales.

La comunicación es fruto del proceso de socialización y posterior función de recreación comunitaria de los individuos; del mar surge el churo para enviar mensajes, del bosque las bambas del carrá, las canoas, los tintes de kipará e imbica, las semillas y los bejucos para llenar de mensajes el cuerpo y las casas y de los individuos la palabra con sus fonemas particulares de un castellano y un embera adaptados a la onomatopeya zonal y los significados del grupo, ligado con la comunidad, con el bosque, el mar y los ríos. La socialización de un niño en la comunidad sigue procesos que para los afro equiparan en el lenguaje algunos de los conceptos de sacramentos católicos, como momentos de crecimiento y apropiación de los compromisos comunitarios dentro de la comunidad eclesial: bautismo de agua, de pila o altar; recibimiento comunitario y acompañamiento en el proceso que le involucra como un individuo recreador de la comunidad, el cual se hace con momentos especiales 


\section{Bioetnia Volumen 11, 2014}

marcados por la primera comunión, la confirmación, el matrimonio. Los Embera tienen otros momentos que marcan el proceso de socialización: el nacimiento, el corte de uñas, el recibimiento comunitario y acompañamiento del crecimiento comunitario diferenciado por género con la fiesta de la muchacha o gemené y la unión en pareja (Quintero 2012).

Las condiciones técnicas para disfrutar con efectividad de los medios de comunicación y lo que trae consigo la tecnología avanzada en el municipio de Nuquí, no están muy actualizadas; pero dentro de lo que se encuentran, estos se pueden analizar en dos niveles, en el ámbito tradicional y en los desarrollos de infraestructura para los medios masivos.

En el ámbito de lo tradicional las comunidades han resuelto la necesidad de comunicarse a través de los llamados recados, mensajes, sonidos y a partir de la constitución de los conglomerados, las reuniones, el megáfono centralizado o móvil por las calles vociferando mensajes de interés comunitario, notándose siempre que prima la oralidad.

Lo que se necesita comunicar ha estado determinado por citaciones a reuniones, convocatorias a fiestas o ritos funerales, avisos varios: la llegada de un personaje, solicitud o novedades en la prestación de servicios comunitarios, entre otros.

En el ámbito de las comunicaciones modernas la región ha avanzado en la instalación parcial de algunos servicios como:

La radio. Es el medio de mayor sintonía para escuchar música principalmente, mientras se está atento a los mensajes enviados desde Quibdó u otros lugares, es el medio "razonero", a través del cual se enteran de una visita o de un fallecimiento en tierras lejanas. Pocas personas se interesan por noticias del orden nacional. La radio ha jugado un papel determinante en lo relacionado con las comunicaciones en las comunidades, porque es el medio de comunicación masivo por excelencia, de fácil manejo, personalizado y produce información de manera inmediata con la realidad. Se puede afirmar sin temor a equivocarnos, que es el medio que más se utiliza para estar enterados de lo que ocurre en otros lugares y enterarse también de lo que ocurre en el lugar donde habitan, de hecho se logra sintonizar emisoras del orden nacional y del orden regional. Las de mayor sintonía son las de Quibdó, en especial Radio Universidad del Chocó, radio Caracol, la emisora del ejército y la policía nacional. Cabe anotar que también se sintoniza la emisora del grupo subversivo Ejército de Liberación Nacional, radio "insurrección". Las comunidades involucradas en el proyecto tienen baja recepción de las emisoras, pocas familias cuentan con radio receptores.

No se tiene con exactitud la fecha de creación del decreto para la instalación de la emisora comunitaria; pero se logra precisar que en el año 2009 el Ministerio de Comunicaciones asignó a la organización comunitaria Consejo Comunitario General Los Riscales del municipio de Nuquí, una frecuencia radial con potencia de 1800 megahertz, para que funcionara en la modalidad de "emisora comunitaria" a la cual se le dio el nombre de "Riscal Estéreo" y que funciona en la frecuencia 105.8 FM.

Para el Ministerio de Comunicaciones la emisora viene funcionando desde la fecha de la asignación; en la realidad la emisora aún no está dotada, pues se inició el proceso de capacitación y apadrinamiento para la emisora comunitaria pero no se logró materializar el proyecto. Inicialmente se logró obtener apoyo de ONGs como Patrimonio Natural, Mar Viva y Swissaid Colombia para la dotación de equipos para la emisora: consolas, transmisores, grabadoras de periodismo y micrófonos. Alma Mater de Pereira (Risaralda) y Parque Natural apoyaron con las capacitaciones; Zulia mena y Jairo Velásquez diseñaron y formularon la parrilla de programación, la cual aún se tiene.

En síntesis, la radio informa a la comunidad sobre acontecimientos y brinda la posibilidad de recreación con música. La emisora comunitaria ha funcionado ocasionalmente y no tiene un plan sistemático que parta de las necesidades de comunicación de las comunidades.

La televisión. Es un medio más restringido que la radio en las comunidades debido a tres factores: falta de capacidad económica para adquirir el equipo, falta de acceso a una buena señal, se requiere estar afiliado a un canal o servidor que cuente con servicio satelital y falta de conocimientos de la tecnología. En el área de la cabecera municipal, se puede obtener este servicio, lo que eliminó las grandes antenas de guadua que permitían tomar un poco de señal en otrora. Entre los canales que se ofrecen están los nacionales Caracol, RCN, Señal Colombia y los regionales Telepacífico, Teleantioquia y CityTV del centro del país. Las comunidades circunvecinas del golfo de Tribugá tienen acceso a la señal pero la frecuencia de sintonía es muy baja, solo algunos maestros observan noticias y uno que otro programa. Este uso está condicionado por dos factores: el ritmo de las faenas de trabajo, durante el día los hombres están en el monte o en mar mientras que las mujeres toda la mañana están lavando ropa en el río o cosechando productos de las parcelas para la alimentación. En la tarde, los hombres, después de regresar a casa, asearse y cambiarse, prefieren jugar a las cartas o el dominó o dialogar a la sombra de los árboles si no llueve o en algunas de las grandes salas-terrazas de las casas, mientras que algunas mujeres liberadas de la cocina accionan la televisión, de las pocas familias que la tienen, para ver alguna novela. El otro condicionante es contar con energía; ninguna comunidad tiene energía permanente, la que más cuenta con el servicio es la cabecera municipal y hasta finales del año 2013, el servicio diario era solamente de 5 horas, de las 6 pm a las 11 pm. Durante el año 2014 


\section{Comunicación afro y embera. JM Guerra, MB Uribe}

se tiene el servicio desde las 9 de la mañana hasta las 12 de la noche. Algunas familias en las comunidades ponen en funcionamiento un pequeño motor de energía con el cual activan la televisión para ver un partido de futbol y particularmente una película a través de DVD entre las que predominan los temas de violencia

En las comunidades la energía solamente se tiene en ocasiones en que por alguna necesidad se compra combustible y se enciende la planta comunitaria, de lo contrario solo algunas familias tienen plantas que las encienden desde las 6 a las $10 \mathrm{pm}$. Contadas familias, en promedio una por comunidad, tiene planta eléctrica para refrigeración encendida tiempo completo y desde estas se presta servicio entre una y cinco familias.

Son pocos los televisores existentes, entre 4 y 5 por comunidad; en la cabecera municipal $70 \%$ de las familias tiene un televisor en casa y los utilizan comunitariamente para ver partidos de fútbol, sobre todo la población juvenil, telenovelas las mujeres adultas y algunas películas de violencia; en pocos televisores ven noticieros en el horario de las 7 de la noche. Existe en la cabecera municipal de Nuquí el canal comunitario Cable Coral, el cual se sintoniza desde hace diez años, pero solo se ha utilizado para pasar información de entidades que lo requieran y de la alcaldía municipal, como se dijo al inicio para hacer invitaciones e informar de funerales o invitación a reuniones como lo hacen por el megáfono. Cable Coral es una sociedad comunitaria que presta sus servicios a la comunidad por un costo mensual de $\$ 15$ mil pesos; a este cable casi el $70 \%$ de la población está afiliado; aunque no se cuente con el servicio de energía las 24 horas del día, los que cuentan con planta se benefician y los que no la tienen solo disfrutan en las horas de la noche, pues en el municipio se presta el servicio de energía de 6 pm hasta la media noche y es en este horario donde se aprovecha para entregar la información a la comunidad.

El teléfono. En un principio, se instalaron teléfonos que se podrían denominar como públicos, en la medida que se recibían llamadas para los habitantes de la comunidad; era un número para el pueblo. Se adjudicaron por poblado a través de la empresa Compartel, sin embargo, con la llegada de la telefonía celular, Comcel estableció señal en forma parcial en la región y se abandonaron las instalaciones iniciales. Todas las comunidades carecen de señal de celular plena, tienen señal en lugares cercanos a los conglomerados con interferencias continuas. Hoy solamente la comunidad de Joví tiene señal con relativa facilidad y frecuencia, mientras que Nuquí Arriba, Tandó y Yucal carecen completamente de señal y Partadó, Termales y Jagua tienen puntos dentro o cercanos a la comunidad en donde, con alguna dificultad, se logra acceder a señal. Pero esto no ha sido impedimento para que a estas poblaciones los equipos celulares les sean atractivos; todas las comunidades tienen celulares, los cuales no siempre se usan para comunicarse, es una especie de bisutería que da prestigio o se usa para escuchar música.

Internet. Solamente en Nuquí se tiene acceso limitado a internet; en la región desde inicios del mes de abril de 2012 se ofrece a la comunidad el servicio de banda ancha, pero a mediados de 2014 no se cuenta con un buen servicio. El servicio de wi-fi no está disponible en la localidad, esta situación es bastante limitante para el servicio turístico y paradógicamente también resulta atractivo para otros que prefieren descansar de lo absorvente que se han vuelto las redes sociales.

Megáfono o perifoneo, utilizado comúnmente en las comunidades con el fin de hacer anuncios sobre un hecho, evento o situación próxima a ocurrir. Por lo general es la misma persona que se encarga de difundir con su voz la información, convirtiéndose en una radio andante y generando algo de ingreso a partir de esa realidad. En Nuquí existió un megáfono centralizado que funcionaba como una especie de emisora pero fue abolido hace muchos años. Actualmente la Junta Administradora de la energía utiliza un megáfono para el anuncio de las novedades sobre el servicio, el cual prestan a otras instituciones para vociferar alguna programación o anuncio de interés comunitario. Se utiliza con un vociferador que se moviliza por todo el poblado haciendo sus anuncios.

Chocó 7 días, es un periódico semanario de gran importancia para la comunidad chocoana en general, cubre gran parte del departamento y se ha convertido en un reafirmante de los hechos que aparecen allí, demostrando el poder de los medios de comunicación, al igual que lo hiciera en su momento la radio: "Sí es verdad, yo lo leí en Chocó 7 días o yo escuche que lo dijeron en la radio". Todos los viernes llegan al municipio de Nuquí alrededor de 100 ejemplares, que aunque son insuficientes para la demanda, se tiende a difundir de boca en boca la información consignada allí, por parte de quienes tuvieron el privilegio de adquirirlo.

En síntesis, en las comunicaciones en el escenario del golfo de Tribugá, municipio de Nuquí, siguen prevaleciendo los medios tradicionales en los que bosque, río y mar constituyen los escenarios que brindan elementos para sus dinámicas. Los medios técnicos tienen presencia con escaso desarrollo por lo que es bastante limitada la respuesta a las necesidades de circulación de información entre los individuos y comunidades. Se identifican tres razones dominantes que limitan las posibilidades de desarrollar medios masivos de comunicación: a) La baja demanda comercial que no ofrece garantías a las empresas de recuperación de la inversión necesaria para optimizar los servicios; b) la baja capacidad de gestión institucional para ofrecer servicios que lleven a beneficiar a toda la comunidad con acceso a información oportuna (Cuervo 2012); y c) el predominio 


\section{Bioetnia Volumen 11, 2014}

de los conocimientos tradicionales en las comunidades, los cuales aún son respuesta a las necesidades más urgentes de comunicación.

Un ejercicio de mejoramiento de las comunicaciones en las comunidades del Golfo de Tribugá debe partir de la valoración de los conocimientos tradicionales, lo cual permitirá enriquecer el uso de medios técnicos, la animación de la radio y la televisión con el manejo de la imagen y el sonido entre los habitantes del golfo permitirá un mayor arraigo cultural y territorial que importar programaciones externas que pueden arriesgar sobre todo los procesos de socialización de las nuevas generaciones

La Conferencia General de la Organización de las Naciones Unidas para la Educación, la Ciencia y la Cultura, reunida en París en octubre de 1989, aprobó la recomendación de salvaguardia de la cultura tradicional y popular; es de resaltar que esta declaración identifica la cultura tradicional y popular como "el conjunto de creaciones que emanan de una comunidad cultural fundadas en la tradición, expresadas por un grupo o por individuos y que reconocidamente responden a las expectativas de la comunidad en cuanto expresión de su identidad cultural y social; las normas y los valores se transmiten oralmente, por imitación o de otras maneras. Sus formas comprenden, entre otras, la lengua, la literatura, la música, la danza, los juegos, la mitología, los ritos, las costumbres, la artesanía, la arquitectura y otras artes". Todos estos elementos ligados con el bosque, ríos y mar en el golfo de Tribugá tienen vigencia y ameritan ser protegidos.

Se trata de promocionar el conocimiento tradicional en dos direcciones, de una parte como sujeto de medios, es decir, cuyos medios responden a las necesidades de comunicación de las comunidades y de la otra como sujeto de "noticiabilidad con sus temas" (Irujo y Blazquez 1987).

Se sugiere emprender acciones paralelas que produzca la valoración de los medios usados desde la cultura tradicional señalados en este artículo y a la gestión del mejoramiento del uso de los medios técnicos emisora comunitaria, televisión, celular e internet.

\section{Literatura citada}

Conferencia General de la Organización de las Naciones Unidas para la Educación, la Ciencia y la Cultura. 1989. Recomendación sobre la salvaguardia de la cultura tradicional y popular. París: ONU.

Cuervo GS. 2012. Diagnóstico de los medios de comunicación en Nuquí. Quibdó: Insituto de Investigaciones Ambientales del Pacífico.

Irujo K, Blazquez L. 1987. La cultura tradicional en los medios de comunicación. Cuadernos de Etnología y Etnografia de Navarra. 19 (49): 27-37.

Mosquera SY. 2012. Custorio de semillas nativas en Nuquí. Nuquí: Insituto de Investigaciones Ambientales del Pacífico.

Quintero GS. 2012. Diagnóstico de la capacidad institucional a nivel localy regional de las entidades decisoras y organizaciones frente a la agrobiodiversidad y conocimiento tradicional asociado en Nuqui. Nuquí: Instituto de Investigaciones Ambientales del Pacífico. 